\title{
Radioanalytics - An Indispensable Tool for Radiological and Nuclear Safety
}

\author{
Dorothea Schumann ${ }^{\star a}$ and Martin Heule ${ }^{b}$
}

\begin{abstract}
The exact knowledge on the inventory of a radioactive sample is a precondition to act appropriately in terms of nuclear safety. Radioanalytical methods aimed to determine the radionuclide content of activated material play therefore a central role regarding safe operation of nuclear installations, protection of personnel, inhabitants and environment as well as for the design and construction of new facilities. The article gives an overview on the broad variety of analysis and measurement methods, describes necessary chemical separation procedures and explains the impact for nuclear safety assessment in the field of radioanalytics at the Paul Scherrer Institut Villigen, Switzerland. It addresses both the safe routine operation of nuclear installations, which can be a challenge to our radiometric capabilities and refers to selected radioanalytical research projects.
\end{abstract}

Keywords: Measurement methods - Nuclear safety · Radioanalytics · Radiochemical separations · Radioprotection

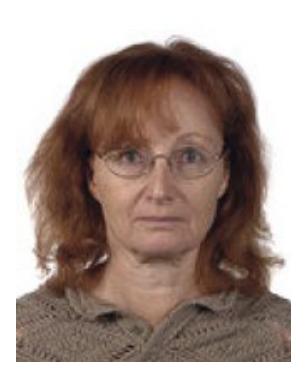

Dorothea Schumann studied chemistry at the Technical University (TU) in Dresden, Germany and obtained her PhD after five years of study at the Joint Institut of Nuclear Research in Dubna, Russia. Up to 1999 she held a position as scientist in the working group Radiochemistry in the Institut for Analytics at TU Dresden, where she studied the chemical properties of Superheavy Elements. After a short intermediate stop as a project manager in the company Wälischmiller she switched to Paul Scherrer Institut Villigen, Switzerland in 2000, where she has been working as group leader of the research group Isotope and Targetchemie since then. Her research interest focus on the production and separation of exotic radionuclides from accelerator waste, their radioanalytics as well as the determination of their decay data (half-lives, branching ratios) and reaction rates.

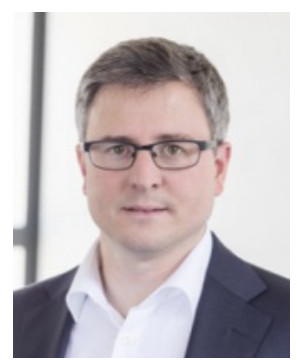

Martin Heule studied Chemistry at the Swiss Federal Institute of Technology Zurich (ETHZ), focusing on analytical and inorganic chemistry. He obtained a $\mathrm{PhD}$ from ETHZ working on microsystems technology at the Institute of Nonmetallic Materials with Prof. Ludwig Gauckler. Following a post-doctoral stay at Imperial College London, he worked for more than 10 years for Metrohm Group of instruments companies in different development roles for chemical sensors. After obtaining an EMBA, he led the Metrohm Autolab potentiostat business in the Netherlands until 2015. Returning to Switzerland, he joined PSI in 2017 as head of the radioanalytics group.

\section{Introduction}

The knowledge of the radionuclide inventory of 'objects of interest', wherever they come from, is the first and most important pre-condition for ensuring nuclear safety. Only with this knowledge, is it possible to take adequate measures to protect personnel, the population and the environment. 'Objects of interest' cover the entire range of matter surrounding us, from activated components and radioactive samples, produced and handled in controlled areas, to the surrounding air, soil, construction material or components foreseen for final or intermediate disposal that have to be analysed and/or monitored. In order to fulfil these basic requirements, sophisticated analytical methods are necessary, as are theoretical predictions in cases where extensive analyses cannot be carried out. Due to this complex character, radioanalytical methods are implemented both in routine application and in nuclear research. With our present contribution, we want to highlight these two aspects of radioanalytical work and illustrate its importance with several examples from our experience at Paul Scherrer Institut Villigen, Switzerland (PSI).

PSI operates various nuclear installations - the high-power proton accelerator HIPA, the spallation neutron source SINQ, the synchrotron light source SLS, the free electron laser Swiss-FEL, a hot laboratory for handling spent nuclear fuels from the Swiss nuclear power plants, several proton therapy facilities, the radiopharmaceutical centre ZRW and the federal interim storage facility BZL, to mention only the most important ones. The number of associated laboratories, where radioactivity is handled in open or closed form, is correspondingly large. Moreover, PSI operated three research reactors in the past, DIORIT, PROTEUS and SAPPHIR, which now are going to be dismantled and disposed. Ensuring appropriate radioanalytics for monitoring personnel, facilities and the environment as well as the characterisation of radioactive materials, components and parts to be disposed of is a basic prerequisite for carrying out any research work with radioactive materials in accordance with legal and official regulations. PSI maintains an accredited laboratory for the routine tasks, the radioanalytics laboratory, allocated in the logistics department (LOG). At the same time, however, a large number of the measuring methods and equipment

\footnotetext{
${ }^{*}$ Correspondence: Dr. D. Schumanna, E-mail: dorothea.schumann@psi.ch

aPaul Scherrer Institut Villigen, Laboratory for Radiochemistry, Forschungsstrasse 111, CH-5232 Villigen PSI, Switzerland

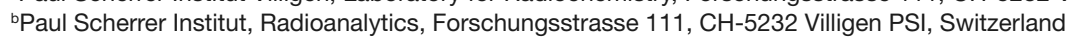


used for routine radioanalytical work are also part of the research work on nuclear physics, geochemistry and radiochemistry, such as determining cross sections of nuclear reactions, repository research, developing radiopharmaceuticals or research in the field of superheavy elements, carried out in several laboratories at PSI, for instance the laboratory for waste management (LES) or the laboratory for radiochemistry (LRC). Conversely, the results and findings obtained in these research areas lead to the improvement of analytical measurement methods, which are later routinely applied. In addition to meeting regulatory requirements, this work is making a decisive contribution to improving the models and codes for the theoretical calculation of residual core production, thus enabling reliable theoretical predictions. The production of a radionuclide vector will then make it possible to save some of the time-consuming radiochemical determinations for components with similar material composition to be disposed of. In Fig. 1, we show how radioanalytical results can influence theoretical predictions and even the design of new facilities.

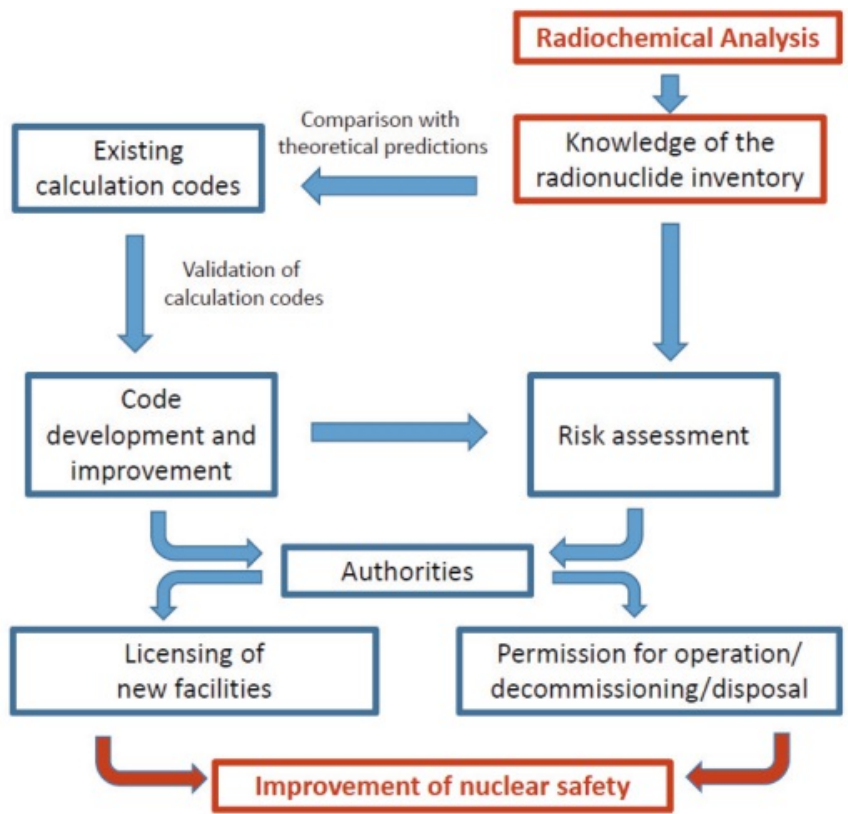

Fig. 1. The interaction of experimental and theoretical research with routine radioanalytical tasks and their influence on risk analysis, decommissioning and disposal, and the design of new facilities.

In the present article, we give a short overview on regulatory demands for routine radioanalysis, illustrated with some examples how routine methods are continuously improved, and thus, research can be carried out with improved analytical methods.

\section{Radioanalytical Methods}

The radioanalytical and radiochemical working groups at PSI own the usual equipment for measuring ionising radiation (detectors for $\alpha, \beta$ and - $\gamma$ radiation, Liquid Scintillation Counting - LSC) as well as the correspondingly equipped monitored laboratories on all activity levels.

Inductively-coupled plasma mass spectrometry (ICP-MS) is used for the analysis of solutions of irradiated nuclear fuels in the hot laboratory. The methods are constantly being improved and further developed, especially with regard to the reduction of sample volumes for waste reduction.

Accelerator mass spectrometry (AMS) is applied for the determination of some long-lived radionuclides emitting radiation that is difficult to measure $\left({ }^{36} \mathrm{Cl},{ }^{10} \mathrm{Be},{ }^{26} \mathrm{Al},{ }^{129} \mathrm{I}\right.$, etc. $)$, which occur in very low concentrations (collaboration with the Institute for Ion Beam Physics at ETH Zurich).
It has to be emphasized that for a considerable number of measurements, the non-destructive methods like $\gamma$-spectrometry or air monitoring using nuclear track detectors are not sufficient. Sophisticated radiochemical separation procedures have to be developed and applied to get the isotope under study into a sample form suitable for the envisaged measurement ( $\alpha$-ray detection, LSC, AMS, ICP-MS).

\section{Radioanalytics at PSI}

\subsection{Routine Analytics}

The radioanalytics laboratory is involved in both emission and immission monitoring at and around PSI. Emissions are direct releases from a specified technical installation into the environment. Immissions are measured at various sites in an environment and will measure naturally occurring radionuclides in combination with radioactivity originating from any anthropogenic source, near or far. Installations like PSI or nuclear power plants monitor their emissions under supervision and several different laboratories are tasked with the monitoring of their environment. The results of the diverse monitoring activities are in the public domain, published by the Swiss Federal Office of Public Health (FOPH, or Bundesamt für Gesundheit, BAG) on a yearly basis in a comprehensive report called 'Umweltradioaktivität und Strahlendosen in der Schweiz'. [1]

PSI has a variety of particle accelerators and beamlines that are under regulatory supervision by the FOPH. In addition, the former nuclear test reactor installations now in various stages of decommissioning, are supervised by the Swiss Federal Nuclear Safety Inspectorate (ENSI). Both authorities have issued technical directives that define the procedures for continuous monitoring of all relevant emission paths, mainly via exhaust air or via waste water. With this type of monitoring, it is important to note that the monitoring is adapted to the continuous measurement of small amounts of radioactive traces produced during normal operation of the facilities. At various points in the ventilation systems, air is sampled through glass filters for aerosol collection, various cartridges containing activated carbon powder and dedicated detectors for the measurement of radioactive noble gases. The filters are changed weekly and analysed individually for the whole range of radionuclides produced at PSI. Wastewater is purified depending on its origin, pretreated and collected in tanks. Every tank content is analysed by the radioanalytics laboratory and verified by radiation protection experts before release. In combination of all releases through air and water, a yearly dose contribution to the public in the area of less than $0.01 \mathrm{mSv} / \mathrm{yr}$ was calculated for 2019.[2]

The radioanalytics laboratory also contributes to the environmental monitoring of immissions in the local area around the institute. Since the nuclear power plants of Beznau are located only $2 \mathrm{~km}$ north of PSI as well as the neighbouring storage facility for radioactive waste, Zwilag, the monitoring area encompasses all installations, PSI, Zwilag and Beznau, in a radius of up to $10 \mathrm{~km}$, mainly along the Aare river valley. There are several collection tools in use. For air monitoring, two air pump stations are operated to continuously draw air at $60 \mathrm{l} / \mathrm{min}$ through a glass filter in order to collect aerosols. In addition, more than 10 waxed plates are installed at about $2 \mathrm{~m}$ above ground at various locations throughout the region to collect dust and organic matter from the air and rain water.

For water collection, there are two additional collecting systems to collect rain water and several collection systems to sample water from the Aare river. The inflow devices of the river water collection systems are equipped with capillaries that allow to sample the water over an extended time period. The samples collected by these systems are brought back to the laboratory in regular intervals. Samples are then analysed for various radionuclides. A summary of parts of the results can also be found in the FOPH report in ref. [3]. 
The environmental monitoring is complemented by grass, tree leaf and soil samples taken once per year. For the soil samples, a full chemical separation for alpha and beta nuclide analysis is performed to measure different $\mathrm{Am}, \mathrm{Cm}, \mathrm{Pu}, \mathrm{U}$ nuclides as well as ${ }^{90} \mathrm{Sr}$.

The laboratory is also responsible for excretion analysis, i.e. the examination of stool and urine samples in order to ensure the monitoring of the personnel regarding incorporation risks.

\subsection{Radioanalytics in Research and Development}

\subsubsection{Environmental Research}

While certain regions in the Swiss Alps are well characterised in terms of elevated natural concentrations of uranium, the fact that also in the Swiss Plateau small pockets of elevated U concentrations can be found is known to a much lesser extent. Geologist A. Pregler ${ }^{[4]}$ studied examples of such occurrences at the interface of the Lower Freshwater Molasse and the Upper Marine Molasse layers during her $\mathrm{PhD}$ thesis that she performed at the radioanalytics laboratory. Such a situation can be found around Mont Vully near the city of Berne. The site was characterised by following the water streams and by analysing soil samples at dedicated locations of importance. Water samples were taken from sources, streams, irrigation systems in the flatland at the foot of Mont Vully and accessible water fountains in the region. Soil samples were obtained by core drilling at locations of elevated dose rates as found in several surveys carrying a mobile and sensitive dose rate detector across the farmland on foot. Combining all results, it was possible to shed light on the geological and hydraulic processes that accumulated the elevated deposits of natural $U$ and to explain how parts of the $U$ concentrations are leaching into surrounding water streams. ${ }^{[4]}$

Accumulation of radionuclides in mushrooms has been a concern for large parts of Eastern Europe since the Chernobyl accident in 1986. The main radionuclides distributed were radioactive ${ }^{137} \mathrm{Cs}$ and ${ }^{134} \mathrm{Cs}$. While ${ }^{134} \mathrm{Cs}$ has already decayed due to its shorter half-life of approx. 2 years, ${ }^{137} \mathrm{Cs}$ can still be detected by gamma spectrometry. However, its distribution within soils due to the constant influence of water and the rates of uptake by different animals and plants are very complex. A joint radioecological survey by the Swiss Federal Research Institute WSL and the Hungarian NEFAG centre collected truffle samples (Tuber magnatum pico) at several locations throughout southern Hungary. These, as well as samples of surrounding soil material were analysed by the radioanalytics laboratory for their ${ }^{137} \mathrm{Cs}$ activity concentrations. Only low levels of ${ }^{137} \mathrm{Cs}$ activity concentrations of less than $5 \mathrm{~Bq} / \mathrm{kg}$ were found in Tuber magnatum samples, despite some soils exhibiting levels up to $67.5 \mathrm{~Bq} / \mathrm{kg}$. ${ }^{5]}$

The radioanalytics group will continue to support selected scientific projects of environmental research.

\subsubsection{Collaborations in Research for Deep Geological Disposal of Radioactive Waste}

Nagra (National Cooperative for the Disposal of Radioactive Waste) is tasked with researching and locating a suitable deposit site for deep geological disposal of radioactive waste. NAGRA operates an extended underground laboratory at the Grimsel Test Site (GTS) south of Berne and supports several research projects in the rock laboratory at Mont Terri in the Jura mountains. The radioanalytics group participated in the long-term diffusion project at GTS by providing the solutions of radioactive tracers, which were circulated inside a bore hole for more than two years. In regular intervals, samples of circulating solutions were quantitatively analysed in order to monitor the depletion of radionuclides from the circulating solution into the surrounding rock. After the exposure phase, a piece of rock surrounding the bore hole was drilled out of the test site and analysed by other project partners. In situ diffusion studies allow the verification of laboratory scale experiments in a more realistic environment as well as the validation of mathematical diffusion models which are important for simulations of long time storage of radioactive waste. ${ }^{[6]}$

Currently, another diffusion study in collaboration with the Rock-Water Interaction Research Group from the University of Berne has been running at the Mont Terri rock laboratory since May 2019. Again, the radioanalytics laboratory prepared the radionuclide tracer mixture for injection into the circulation system and is periodically analysing the depletion of nuclides into the rock during the experiment.

\subsubsection{Analytical Research and Development of Dedicated Analytical Procedures}

Despite all the field applications discussed above, there is still a need for further development and room for improvement of analysis procedures. Chemical separation is necessary for radionuclides that have no significant gamma emissions. As decommissioning is dealing with a variety of materials and waste mixtures, the challenges for a high quality chemical separation remain.

This was demonstrated recently by an important optimization project to analyse barite concrete samples from nuclear decommissioning projects for various alpha and beta nuclides. Barite concrete is a type of reinforced concrete with $\mathrm{BaSO}_{4}$. It is used to shield nuclear reactors more efficiently. When dismantling nuclear reactors, a fair number of barite concrete samples has to be expected. Barite is especially hard to dissolve chemically in order to release the radionuclides embedded in the material. In an effort to avoid the use of hydrofluoric acid, a fusion technique based on dissolving a powdered barite concrete sample in a mixture of Li-metaborate and Li-tetraborate at temperatures of $1100{ }^{\circ} \mathrm{C}$ was used. However, in order to guarantee good chemical yields, the separation sequence after the fusion melting process had to be optimized. Based on tracer recovery studies, chemical yields averaged over 6 samples of up to $86 \%$ could be obtained for ${ }^{242} \mathrm{Pu}$, up to $63 \%$ for ${ }^{243} \mathrm{Am}$ and up to $67 \%$ for ${ }^{85} \mathrm{Sr}$. This technique allows barite concrete samples to be analysed for otherwise hard-to-detect nuclides on a routine basis using only small amounts of sample. ${ }^{[7]}$ Fig. 2 shows details of the practical work to be performed for the determination of ${ }^{63} \mathrm{Ni}$.
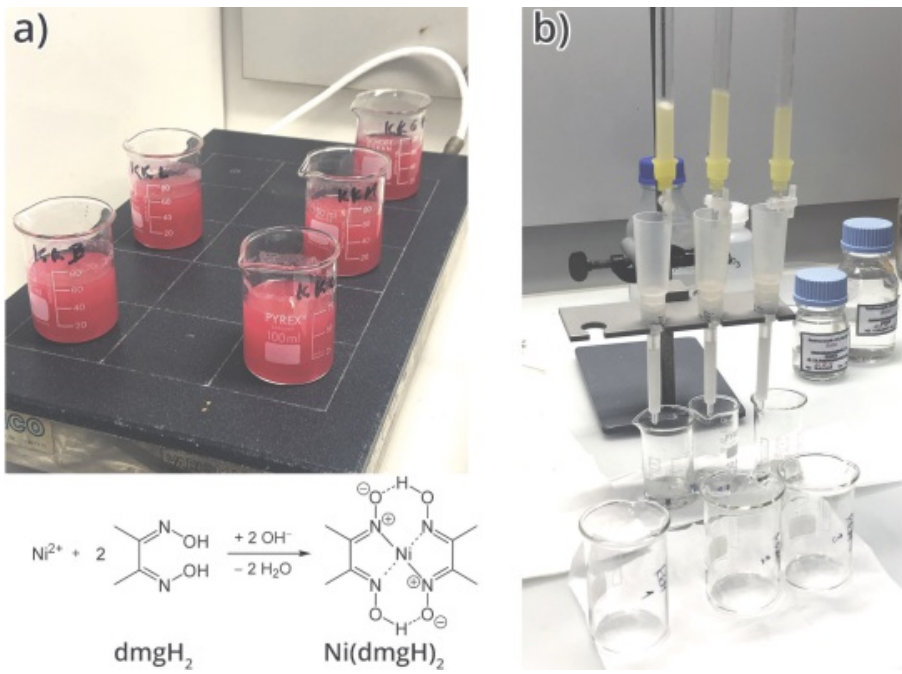

Fig. 2. a) Radioactive traces of ${ }^{63} \mathrm{Ni}$ can be chemically separated by using the classical precipitation reaction with dimethylglyoxime $\left(\mathrm{dmgH}_{2}\right)$. It forms a bright red complex with $\mathrm{Ni}^{2+}$ which is insoluble in water and can be filtered easily. In the field of radioanalytics, the most important feature of this precipitation is the high selectivity against other bivalent cations such as ${ }^{55} \mathrm{Fe}^{2+}$ and ${ }^{60} \mathrm{Co}^{2+}$ which would be interfering radionuclides in subsequent liquid scintillation counting analysis. b) Example of the use of a stack of two chromatographic columns for the chemical separation of radionuclides, as detailed in ref. [7] 


\subsubsection{Special Analytics of Accelerator Waste}

PSI operates one of the most powerful proton accelerators in the world, the proton accelerator HIPA. The components in the surroundings of this facility, which are intended to be dismantled and disposed of after a certain time of usage, are correspondingly highly activated. This comprises targets like the rotating carbon wheels for muon production or the lead targets of the neutron spallation source SINQ as well as all activated structure and shielding components in direct neighbourhood of the facilities. The radionuclide inventory of such waste differs significantly from that in spent fuel elements. Besides the commonly investigated radionuclides (e.g. ${ }^{60} \mathrm{Co},{ }^{137} \mathrm{Cs},{ }^{54} \mathrm{Mn}$ or ${ }^{152} \mathrm{Eu}$ ), the Swiss authorities pay special attention to long-lived nuclides like ${ }^{14} \mathrm{C},{ }^{10} \mathrm{Be}$ or ${ }^{36} \mathrm{Cl}$.

In order to meet the requirements of the authorities, new separation and measurement methods have been developed, many of them within the framework of scientific work and international collaborations. Examples are the determination of the radionuclide inventory of the Cu-beamdump BMA, ${ }^{[8]}$ the MEGAPIE target, ${ }^{[9-13]}$ one of the Pb-targets from the SINQ ${ }^{[14-16]}$ and a comparison of the ${ }^{14} \mathrm{C}$ content in power plant steel and the structural materials of the SINQ. ${ }^{[17]}$ This last example is described in more detail below to illustrate how such radioanalytics work is performed:

One of the options for treating nuclear waste is the so-called Accelerator-Driven System (ADS), where high-energetic neutrons, produced by accelerated protons hitting a heavy metal target, are used to transmute long-lived radionuclides stemming from the spent fuel of Nuclear Power Plants (NPP), into shorter or stable isotopes. However, while such radioactive waste from NPP can be burned under safe conditions, because it is a not self-sustained nuclear reaction, the target complex itself is highly activated - a fact that is often neglected when discussing the advantages of ADS. Therefore, we triggered a direct comparison experiment with steel samples from the SINQ facility at PSI (which is similar to the neutron source of an ADS) and a Swiss NPP (Gösgen) (photographs of selected samples shown in Fig. 3) to evaluate the induced radioactivity, in particular also regarding long-lived hard-to-measure radionuclides, in this case with ${ }^{14} \mathrm{C}$ as an example. The irradiation times and power levels for the NPP and the SINQ samples were comparable with around two years for both. We performed $\gamma$-measurements for the determination of the main dose contributors ${ }^{54} \mathrm{Mn}$ and ${ }^{60} \mathrm{Co}$ and used Liquid Scintillation Counting (LSC) after wet digestion and an elaborated radiochemical separation system to quantify the ${ }^{14} \mathrm{C}$ content. Interestingly, the induced ${ }^{14} \mathrm{C}$ activities in the SINQ samples were mainly in the same order of magnitude of the ones from the NPP. The results for the $\gamma$-emitters ${ }^{54} \mathrm{Mn}$ and ${ }^{60} \mathrm{Co}$ were more complex. While the SINQ samples showed at least two orders of magnitude higher values for the ${ }^{54} \mathrm{Mn}$ production, the ${ }^{60} \mathrm{Co}$ content was a factor 10 higher for the NPP samples. The values are in fair agreement (within a factor 4) with theoretical predictions using MCNP calculations. Taking into account the different steel compositions and the irradiation positions, we could convincingly demonstrate that the activation of structure material in a high power spallation source is comparable to that in a nuclear power plant. Details of the measurements and results can be found in ref. [17].

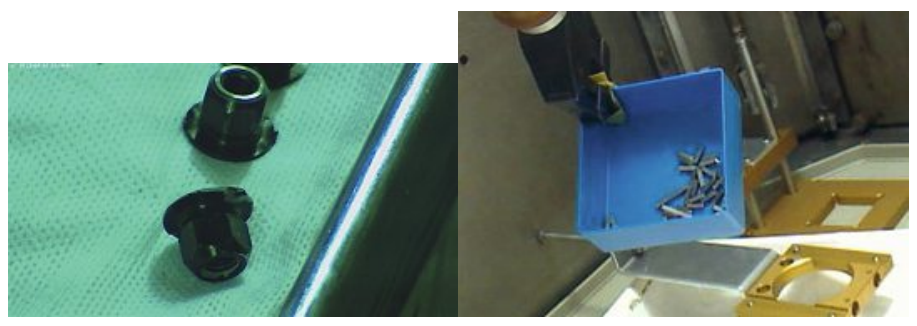

Fig. 3. Left: An activated steel nut from the Nuclear Power Plant Gösgen. Right: Activated steel samples from the material research program STIP (SINQ Target Irradiation Program $\left.{ }^{[18]}\right)$, which were used in the experiment.

\section{Summary and Conclusions}

With this article, we gave an overview of the present requirements to ensure nuclear safety in a research institute running different nuclear installations and handling different kinds of radioactive substances on different activity levels as well as current scientific research projects aimed to improve the radioanalytical methods. With some examples, we have shown how radioanalysis works and what difficulties have to be overcome to obtain the necessary data.

With the introduction of the new Radiation Protection Ordinance 2018 and Switzerland's withdrawal from nuclear energy, radioanalytical work will become increasingly important in the future. The lowering of the limit values for many radionuclides will entail greatly increased measurement effort, which will not only have an impact on the decommissioning of nuclear power plants, but will also present new challenges for radioanalysis in research institutes. The development of new analytical methods to determine even difficult-to-measure radionuclides will become more important. In this context, radiochemical separation and sample preparation methods will be assigned increasing importance to ensure the necessary manufacturing of measureable samples for LSC, ICP-MS or AMS. In collaboration with all the laboratories involved at PSI (Laboratory for Radiochemistry, Hotlaboratory, Radiopharmaceutical Centre, Laboratory for Repository Safety, Radioanalytical laboratory, Group Target Facilities, Beamlines and Simulation) and with the partners (ENSI, NAGRA; NPPs, BAG, ZWILAG, IRA, Fachverband Strahlenschutz e.V, ETHZ, Laboratory Spiez), these development activities must be planned, coordinated, financed and driven forward, whereby the close interaction between research, development and service is the basic prerequisite for fulfilling the demanding future tasks. One of the most important aspects regarding this indispensable development is the further education of young researchers, which can take over the challenging tasks in the future on a basis of profound scientific and technical knowledge and elaborated skills.

\section{Acknowledgements}

A considerable number of present and former colleagues from the PSI labs contributed to this summary of analytical work. We express our gratitude to them all for their excellent work. We especially thank the following colleagues for their exceptional contributions: Bernadette Hammer-Rotzler, Tanja Wieseler, Maja Jäggi and Anja Pregler. Our thanks go also to co-authors of the publications we reviewed. Moreover, the authors wish to recognise the significant contributions of the former head of the radioanalytics group Dr. Jost Eikenberg, who passed away unexpectedly in 2017. The works described here were partly funded by national and international funding agencies: SNSF, SWISSNUCLEAR and the European Commission in the framework of FP7.

Received: July 30, 2020

[1] BAG, 'Annual Report on Radioactivity and Radiation Doses in the Swiss Environment', 2019, https://www.bag.admin.ch/bag/de/home/das-bag/publikationen/taetigkeitsberichte/jahresberichte-umweltradioaktiviaet.html

[2] BAG, 'Annual Report on Radioactivity and Radiation Doses in the Swiss Environment', 2019, p. 137, https://www.bag.admin.ch/bag/de/home/das-bag/ publikationen/taetigkeitsberichte/jahresberichte-umweltradioaktiviaet.html

[3] BAG, 'Annual Report on Radioactivity and Radiation Doses in the Swiss Environment', 2019, p. 153, https://www.bag.admin.ch/bag/de/home/dasbag/publikationen/taetigkeitsberichte/jahresberichte-umweltradioaktiviaet. html

[4] A. Pregler, H. Surbeck, J. Eikenberg, S. Werthmüller, S Szidat, A. Türler, J. Environ. Radioactivity 2019, 208, 106026, https://doi.org/10.1016/j.jenvrad.2019.106026

[5] U. Büntgen, M. Jäggi, S. Egli, M. Heule, M. Peter, I Zagyva, P. J. Krusic, S. Zimermann, I. Bagi, Environ. Poll. 2019, 252, 1643e1647.

[6] J. Ikonen, P. Sardini, L. Jokelainen, M. Siitari-Kauppi, A. Martin, J. Eikenberg, J. Radioanal. Nucl. Chem. 2016, 310, 1041, https://doi.org/10.1007/s10967-016-4890-6

[7] M. E. Jäggi, M. Rüthi, J. Eikenberg, J. Radioanal. Nucl. Chem. 2019, 322, 1279, https://doi.org/10.1007/s10967-019-06854-6 
[8] D. Schumann, J. Neuhausen, J. Eikenberg, M. Ruthi, M. Wohlmuther, P.W. Kubik, H.A. Synal, V. Alfimov, G. Korschinek, G. Rugel, T. Faestermann, Radiochim. Acta 2009, 97, 123, https://doi.org/10.1524/ract.2009.1585

[9] B. Hammer-Rotzler, PhD thesis, University of Bern, 2015.

[10] B. Hammer J. Neuhausen, V. Boutellier, H.P. Linder, N. Shcherbina, M. Wohlmuther, A. Türler, D. Schumann, J. Nucl. Mat. 2014, 450, 278 , https://doi.org/10.1016/j.jnucmat.2013.09.016

[11] B. Hammer-Rotzler, J. Neuhausen, V. Boutellier, M. Wohlmuther, A. Türler, D. Schumann, Anal. Chem. 2015, 87, 5656, https://doi.org/10.1021/acs.analchem.5b00955

[12] B. Hammer-Rotzler, J. Neuhausen, C. Vockenhuber, V. Boutellier, M. Wohlmuther, A. Türler, D. Schumann, Radiochim. Acta 2015, 103, 745 https://doi.org/DOI 10.1515/ract-2015-2420

[13] B. Hammer-Rotzler, J. Neuhausen, V. Boutellier, M. Wohlmuther, L. Zanini, J.-C. David, A. Türler, D. Schumann, Eur. Phys. J. Plus 2016, 131, 233, https://doi.org/10.1140/epjp/i2016-16233-1

[14] T. Lorenz, PhD thesis, University of Bern, 2015.

[15] T. Lorenz, D. Schumann, Y. Dai, Radiochim. Acta 2013, 101661 https://doi.org/10.1524/ract.2013.2067
[16] T. Lorenz, Y. Dai, D. Schumann, A. Türler, Nuclear Data Sheets 2014, 119 , 284, https://doi.org/10.1016/j.nds.2014.08.078

[17] D. Schumann, T. Stowasser, B. Volmert, I. Günther-Leopold, H. Linder, E. Wieland, Anal. Chem. 2014, 86, 5448, https://doi.org/10.1021/ac500654a

[18] Y. Dai, G.S. Bauer, J. Nucl. Mat. 2001, 296, 43, https://doi.org/10.1016/S0022-3115(01)00544-X

\section{License and Terms}

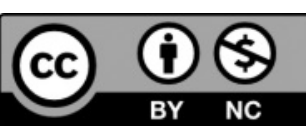

This is an Open Access article under the terms of the Creative Commons Attribution License CC BY_NC 4.0. The material may not be used for commercial purposes.

The license is subject to the CHIMIA terms and conditions: (http:// chimia.ch/component/sppagebuilder/?view=page $\& i d=12$ ).

The definitive version of this article is the electronic one that can be found at https://doi.org/10.2533/chimia.2020.995 